\title{
Sexual and reproductive health issues of youths on the streets in Zimbabwe: the case of Harare Central Business District
}

\author{
Henry Nyararai Chikova ${ }^{1}$ \& Rumbidzai Jeniffer Chikova ${ }^{2}$ \\ ${ }^{1}$ Demographer and ILO Social Protection/Social Security Consultant. \\ ${ }^{2}$ Master in Population Studies Graduate. \\ Email: henrynyararai@gmail.com
}

\begin{abstract}
Background: Youths living on the streets of Harare engage in risky sexual behaviours, which exposes them to sexually transmitted diseases, yet they do not have adequate access to Sexual and Reproductive Health (SRH) services. The study investigated sexual and reproductive health issues among youths on the streets of Harare's Central Business District.

Data and methods: The study interviewed 202 youths and had components of of in-depth interviews and Focus Group Discussions.

Findings: Almost all youths had engaged in sex and had debuted at very young ages. Educational attainment was associated with current sexual activity; so was contraceptive use with drug use and alcohol consumption. Alcohol exposed youths to prenancy. Unsafe abortions were common among female youths - half had suffered an STI. Youths abused drugs and alcohol. Street youths had poor access to SRH services.
\end{abstract}

Conclusion: Government should extend sexual education to street youths, keep them in school and make SRH services easily accessible to them.

Keywords: Youths, Streets, Sexual and Reproductive Health, sexual behaviour, Sexually transmitted diseases, alcohol and drugs.

\section{Introduction}

Youths who live on the streets, also known as homeless youths, are often described as unaccompanied youths aged 12-24 years who are on their own without familial support or stable and adequate residence (Centre for American Studies, 2010). Youth homelessness is occurring the world over (United Nations, 2016). According to UNICEF (2016) there was an estimated five thousand youths on the streets in Harare. Generally youths in developing countries are at high risk of sexual and reproductive ill-health because of harsh economic conditions prevailing in their countries (World Health Organisation, 20I5). The risk is much higher for youths on the streets because they face more aggravated circumstances related to sexual and physical victimization as well as lack of parental guidance and poverty (Volpi, 20I4). They are at a high risk of sexual and physical abuse, sexual exploitation, chemical and alcohol dependency, early mortality and are viewed as dirty, aggressive, violent and dangerous (Volpi, 20I4). Homelessness in youth can lead to serious mental and physical health problems and it can affect normal development and long-term attainment of youth. Additionally, without appropriate intervention and services homeless adolescents are at high risk of early mortality (Chikoko, et al., 20l6).

In Zimbabwe, youths face sexual and reproductive health challenges. These include lack of sex education, parental guidance and access to reproductive health services. Although youths living on the streets face similar challenges their situation is more precarious due to lack of parental or guardian support. By living on the streets they lack parental guidance, supervision and control. These challenges are also as a result of early sexual engagement and alcohol and drug use which leads to risky sexual behaviour. Additionally, there is dearth of data on sexual and reproductive health ( $\mathrm{SRH}$ ) issues among street youths in Zimbabwe. Studies have been conducted but they did not look at SRH issues among street youths. Ruparanganda (2008) studied sexual patterns among street children and Ngwenya (2016) studied adolescent girls' knowledge of their health. These studies did not delve deeper into SHR issues of street children.

Harare, the capital city of Zimbabwe, is host to a number of youths living on its streets, and these youths are exposed to sexual and reproductive health problems, yet research has largely ignored them. They are exposed to contraction of STIs such as HIV. This study seeks to investigate sexual and 
reproductive health issues of this special group of youths. It will also contribute towards recommendations on addressing $\mathrm{SRH}$ issues among street youths.

The study seeks is to investigate sexual and reproductive health issues among youths on the streets of Harare's Central Business District. Specifically the study investigates the youths' sexual behaviours and current sexual activities, their use of contraception, risks associated with pregnancy and abortion among female youths, their knowledge of the risks associated with Sexually Transmitted Infections and HIV and AIDS, the extent of alcohol and drug use and how they affect their sexual behaviours and their access to Sexual and Reproductive Health services.

\section{Literature review and Theoretical Framework}

The UNDESA (20/3) opines that sexual and reproductive needs of the youths are largely unmet. According to Conklin (20I2), globally, most youths who live on the streets experience sexual and reproductive health challenges, which include early sexual debut, lack of use of contraceptives, pregnancy and STIs, including HIV. Exposure to unprotected sex among youths in sub-Sharan Africa has been highlighted by Kumi-Kiyereme, Awusabo-Asare and Dareth (2014) who pointed out risks associated with it such as unwanted pregnancy, unsafe abortions, and dropping out of school. Although access to SRH is low in Africa, at 25\%, it is much lower in Zimbabwe, at $15 \%$ (Mutemasango, 20I4). This situation is direr among street youths who have limited access to SRH services, as they lack parental guidance and face lots of peer pressure.

\section{Sexual behavior}

Sexual debut is early among youths in sub-Saharan Africa (Woog \& Kagesten, 2017). In Malawi $85.9 \%$ of street youths were having sexual intercourse before age 15 (ICF International \& NSO, 2017) while a similar pattern was also found in Lesotho, with $76 \%$ having had sexual intercourse by the age of 14 years (UNICEF, 20I6). ZIMSTAT and ICF (2016) reported the mean age at first sex of 18.6 years for females and 19.6 years for males, in the general population, which is much higher than that of youths on the streets. Early sexual debut among the youths has been explained by early entrance into puberty (James, et al., 2012) and biological changes in adolescents affecting their sexual and reproductive health decision making and behaviour (Muller \& Moult, 20I4).

Additionally peer pressure among street youths is detrimental to their reproductive health and can increase chances of engaging in risky sexual behaviour (Widman, et al., 20l6). Youths on the streets attach meaning to sex. This includes comfort sex, sex for power, sex for punishment and initiation (Watson, 20II).

In sub-Saharan Africa educational attainment among males was found to be positively associated with higher coital frequency and multiple partners (Zuilkowski \& Jukes, 20II). Zuilkowski \& Jukes (20II) found mixed results on the relationship between educational attainment and sexual activity, when they reviewed studies that were carried out in sub-Saharan Africa, on the subject. Some studies found an association between higher educational attainment and higher likelihood of men and women having multiple partners, others established lower likelihood, and others did not find statistically significant relationships.

\section{Contraceptive use}

Margaret and Chafetz (20I5) noted that adolescents rarely use contraceptives when having sex thereby exposing themselves to a greater risk, than older people, of acquiring sexually transmitted infections, unintentionally falling pregnant, and unsafe abortions. Ministry of Health and Child Care (2016) reports that $48 \%$ of sexually active adolescent girls in Zimbabwe aged 15-19 years who had sex in the last 12 months used contraceptives. In sub-Shaharn Africa the rate is $38.6 \%$ (Sanchez-Paez \& Ortega, 2018). Low contraceptive use among the youth has been ascribed to poor quality or non-existence of sexual education targeted at the youth, stigma placed on women and young people who use contraception, cultural pressure on women to have children, women's lack of decision making authority regarding their sexuality, interruptions in governmental or private supply of contraceptive methods that make it difficult for individuals to consistently access contraceptives, and incorrect methods of use or discontinuation because of side effects (Creanga \& Hartman, 2015). According to Okonofua (2016), condom use during sex is a significant indicator of the extent to which youth are able to protect themselves from sexual and reproductive health mishaps during sexual intercourse.

A study among young women in Malawi indicated that age, region of residence, marital status, education, religion, work status, a visit to health facility, and knowledge of the ovulatory cycle are significant predictors of contraceptive use among young women (Mandiwa, et al., 20।8).

\section{Early marriage}

Child marriage is a manifestation of gender inequality, reflecting social norms that perpetuate discrimination against girls. According to UNICEF (20I6), girls are married before they are physically or emotionally 
mature enough to become wives or mothers. Child marriages remain a serious obstacle to the realization of all rights for young people, notably adolescent girls and young women, and have direct and negative impact on their education, health and social status (UNICEF, 2016). All African countries are faced with the challenge of child marriage, ranging from $3 \%$ in Algeria to $76 \%$ in Niger. According to UNICEF (2016), child marriage is widespread in West and Central Africa (42\%) as well as Eastern and Southern Africa (36\%). While some boys are also married as children, girls are disproportionately affected (UNICEF, 20I6).

\section{Pregnancy}

Ministry of Health and Child Care (2016) found that even though age-specific fertility rates among women aged 20 years and above in Zimbabwe have fallen over the last two decades, adolescent pregnancy is on the rise. Zimbabwe Demographic and Health Survey (ZDHS) data, for various years, has shown an increase in adolescent fertility from 99 births per I,000 women aged 15-19 in 2005-06 to 115 births per 1,000 women aged 15-19 in 2010 and slight reduction to 110 per 1,000 in 2015-16. According to UNICEF \& ZIMSTAT (20I4), about a fifth of women aged 20-24 years had at least one live birth before age 18 years.

Research has shown that misconceptions about pregnancy have also increased the rate of teenage pregnancy, where beliefs, such as having a bath soon after having unprotected sexual intercourse avoids pregnancy, are upheld (Wekwete, 2010). Findings reported by Bhatasara, et al., (2013) in their study done in Kuwadzana Extension in Harare, pointed to the belief among adolescents that one cannot get pregnant in the first sexual encounter. Some risk behaviours among adolescent females have exposed them to the risk of pregnancy. Results reported by Moyo \& Zvoushe (20l4) reveal that adolescents in the Mbare District of Harare were involved in unprotected sexual activities as a way to cement their relationships. Similar findings have also been reported by Bhatasara, Changadeya and Chevo (2013).

Due to cultural beliefs and societal attitudes, many adolescents do not use protection as they fear that condom use might raise questions from their partners about being sexually active and whether they have good moral values (Clement, 1992). Insufficient knowledge regarding the use of contraception contributes to unwanted pregnancies among Zimbabwean adolescents (UNFPA, 2016). UNICEF (2016) also reported that, unwanted pregnancies were common among female youths on the streets.

\section{Abortions}

Induced abortions are a consequence of unwanted pregnancy (UNICEF, 20I6). An average of 2.5 million adolescents globally undergo unsafe abortions and $14 \%$ of these occur in low to middle income countries. Research has found that the danger of developing complication is considerably higher among younger women as compared to older women (UNICEF, 2016). Additionally, the prevalence of stillbirths, and death of infants in the first week of birth for mothers aged less than 20 years was $50 \%$ higher than that of mothers aged between 20 to 29 years (UNICEF 20I6). Besides the risk posed on life and health, early marriages and teenage pregnancy affect young women's education and empowerment, as most young women are disturbed from continuing with their school and work after marriage and pregnancy. It has been demonstrated that delaying adolescent pregnancy could strikingly help in enhancing adolescent health, population control and resultantly, social and economic development (World Health organization, 2016). The extent of adolescents who at some point had ended a pregnancy was $5 \%$ in rural areas and $2.5 \%$ in the urban areas (Ministry of Health and Child Care 2016). Abortions are however illegal in Zimbabwe unless the pregnancy threatens the mother's life was a result of rape.

\section{Sexually transmitted infections (STIs) including HIV and AIDS}

The spread of sexually transmitted diseases is influenced by social, economic and behavioral factors. Such factors may present a genuine obstacle to the prevention of STls owing to their effect on social and sexual links, provision and access to health care, readiness to seek care, and social norms relating to sex and sexuality (Center for Disease Control and Prevention, 2017). In Zimbabwe, around 3.2\% of female youths $15-19$ and $2.5 \%$ male teenagers of a similar age were found to have had an STI in 201I (Ministry of Health and Child Care 2016).

Approximately three million new cases of Chlamydia occur every year in Zimbabwe (Ministry of Health and Child Care, 2016). Of all the cases in female patients, half occur in girls aged 15-19 years. Both Chlamydia and Gonorrhoea increase the risk of HIV infection by three- to five-fold (Ministry of Health and Child Care, 2016). If untreated, $10 \%$ to $40 \%$ of women with Chlamydia and up to $20 \%$ of women with Gonorrhoea develop pelvic inflammatory disease (PID) (World Health organization, 2016). Gonorrhoea and chlamydia account for one-quarter to three-quarters of the acute PID cases in young women (Ministry of Health and Child Care, 20I6). PID often leads to infertility, pelvic pain, and ectopic pregnancies. 
In spite of the decline in HIV prevalence in Zimbabwe, young women, especially those living on the streets, are more susceptible to HIV infection because of their early sexual debut, and poverty and the inability to negotiate for safe sex (Ministry of Health and Child Care, 20I6). Knowledge about HIV/AIDS is also low (UNICEF, 2016).

Youths living with sexual and reproductive health related issues come from the world's poorest regions and are at risk of poverty, which may include lack of access to education, economic opportunities and health related services (UNICEF, 20I6). Zimbabwe is among those countries which are experiencing political instability and high levels of poverty, impacting on the prevalence of HIV/AIDS amongst adolescents, especially those living in the streets.

\section{Lack of parental support}

In sub-Saharan Africa traditional and socio-cultural norms are a hindrance to adolescents discussing pubescence and sex with their guardians, parents or teachers (World Health organization 2016). The situation is compounded by lack of proper knowledge on sexual and reproductive health by the parents or guardians (Mburu, et al., 2014). Adolescents' development is characterised by their cognitive, emotional, moral and social identity. These young people suffer confusion because of exposure to new experiences and they may experience loss of identity (George, 2009). These circumstances are direr for street youths who frequently lack information and are faced with poor comprehension of sexual and reproductive health, which when combined with their risk taking and experimenting behaviors, exposes them to sexual and reproductive health problems.

\section{Lack of information about reproductive health}

Youths appear to be poorly informed with regard to their own sexuality, physical well-being, health, and bodies. Cultural and contextual factors, policy factors, resource constraints and school-level factors have been identified as contributors to this lack of information (lyer, et al., 20I4). In Sub-Saharan Africa common misperceptions and poor knowledge about the prevention of unintended pregnancy and HIV have also been found (United Nations Population Fund, 20/3). Other studies have found compartmentalised sex knowledge sharing between parents and children where discussions largely were about avoiding pregnancy (Svodziwa, 2016).

Restrictive laws and policies have been identified as barriers to adolescents' practice of their reproductive health rights. Government officials often enact laws and formal policies that limit their access to reproductive health care (Guttmacher \& Marfatia, 2016). Further, even where no formal restrictions exist, many health workers refuse or are reluctant to provide unmarried or childless young people, especially young women, with information on reproductive health and contraceptives (Svodziwa, 2016). Sehnem, et al. (2018) found out that adolescents have built up their knowledge about sexuality, especially through relationships with friends and older family members, or through access to media sources. Schools and health services were aslo found to be spaces for sharing information about biological aspects of sexuality.

\section{Alcohol and drug use}

Alcohol and Drug use are common among youths on the streets worldwide. In Africa, generally, and in Zimbabwe in particular, $78 \%$ and $79 \%$ of youths on the streets use drugs and alcohol, respectively (Ruparanganda, 2008). Alcohol and substance abuse are common risk behaviours amongst adolescents, as it opens them to opportunistic infections as a result of suppressed immune system (Gemechu, et al., 2009). Gemechu, et al. (2009) noted that adolescents who are under the influence of alcohol may choose to engage in unprotected sex, putting their sexual partners at risk of contracting sexually transmitted ailments.

\section{Access to SRH services}

Findings by UNICEF (20I6) highlighted that only a small proportion of sexually active street youths have access to comprehensive SRH services. Globally, $48 \%$ of street youths have access to SRH services (World Health organization, 2016). According to the same source's guidelines, health services describe all the organisations, institutions, and resources that a society devotes to improving, maintaining, or restoring health. In Zimbabwe, existing services that adolescents can access include clinics, public and private hospitals, and medical practitioners. However, adolescents do not seek reproductive services for a variety of reasons. They fear that their parents might learn of their visits, they are embarrassed that they need or want these services, and they are also put off by the lack of confidentiality and privacy among health services staff (Ministry of Health and Child Care 2016).

Most health care services in Harare City are reported to be inaccessible, unavailable and unaffordable, especially to youths in the streets, and do not respect the privacy of patients (Mangwentsu, et al., 2015). The user-fee system prevents most underprivileged, including street children from accessing health services. 


\section{Theoretical framework}

The theoretical framework for this study is borrowed from (Bachanas, et al., 2002). The framework includes both risk and protective factors for people who engage in risky sexual behaviour. Risk factors include coerced sex, substance use and early sexual debut. In between risk factors and risky sexual beaviour are protective and risk factors. These include peer norms, which form the social/environment factors, HIV knowledge and sexual self-efficacy, which constitute knowledge and skills. We add to this model factors that can introduce risk or protection like living conditions, poverty, educational attainment, marital status, religion and other background factors.
According to this model factors like coerced sex, substance use and early sexual debut lead to youths engaging in more risky sexual behaviour. It is also hypothesized that young people who have higher levels of HIV knowledge, will have more confidence in their ability to practice safer sex (i.e. sexual selfefficacy). Sexual self-efficacy refers to the state of affairs where one can make decisions about what happens to her sexually - to know how to say yes and no to sexual behaviours that expose them to risky sex. Shewmaker (2015) explains that sexual selfefficacy is a competence best built by parents, which, in this case, is lacking among street youths

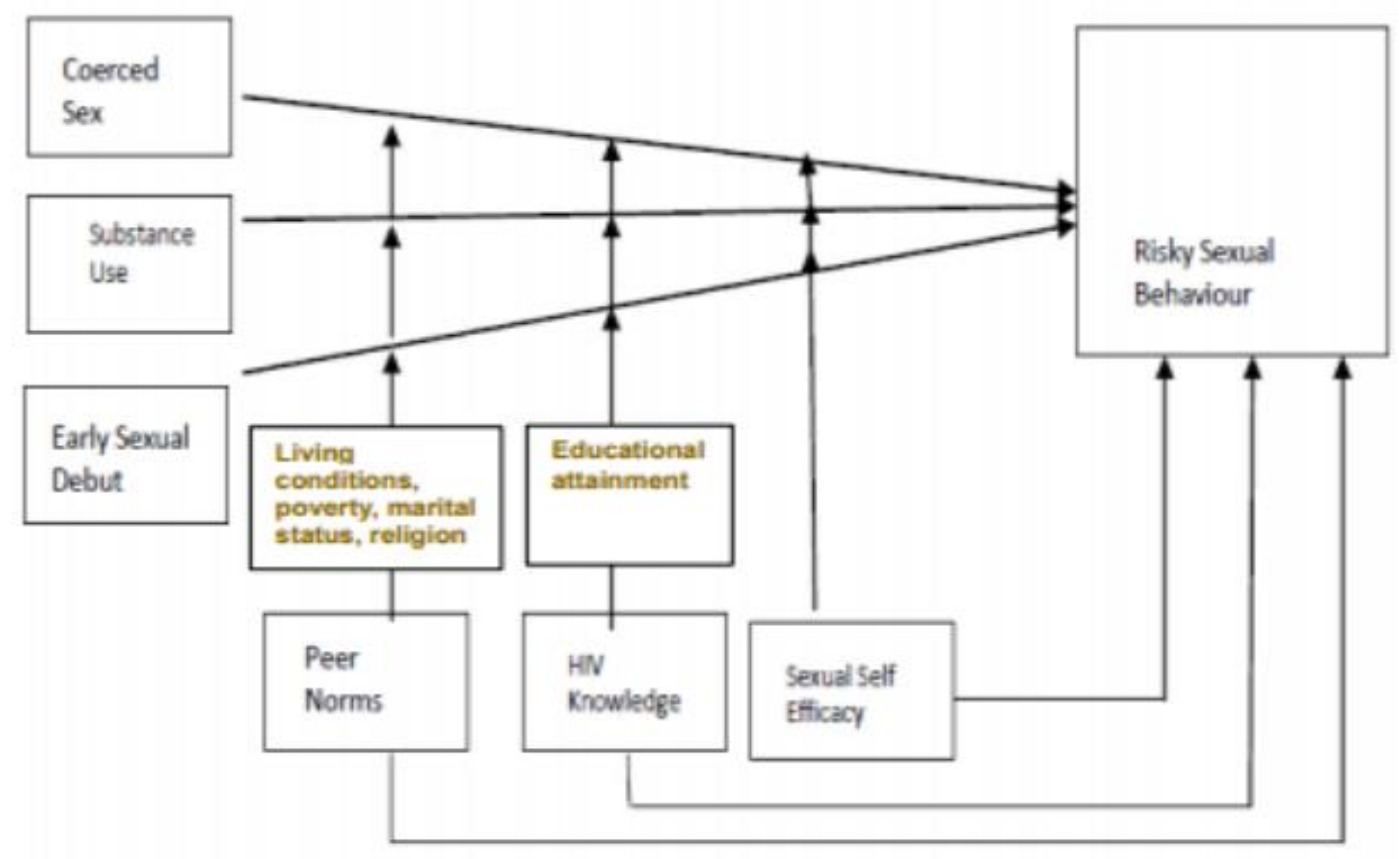

Risk factors

SocialEnvironment

Knowledge and Skills

Figure I. Risk and protective model for predicting risky sexual behaviour (Adapted from Bachanas, et al., 2002)

\section{Data and Methods}

The study was carried out in the Central Business District (CBD) of Harare, the capital city of Zimbabwe. The total number of youths on the streets of Harare is estimated to be 5,000 (UNICEF, 2016). The study targeted youths aged I2-24 years living on the streets of Harare CBD. The population varied in terms of religion, marital status and level of education. The study was cross sectional.

A survey, augmented by in-depth interviews and Focus Group Discussions, was used to collect data on http://aps.journals.ac.za sexual and reproductive health issues among street youths. Four Focus group discussions were conducted in the study and each focus group consisted of 8-12 participants. Age cohorts were used for selection of respondents. The FGDs were divided as follows: Two FGDs comprised of males aged 12-14 years and females aged $12-14$ years. The other two FGDs comprised of males aged 15-20 years and females aged 15-24 years. The group of participants was guided by a facilitator who introduced the topic and helped the group to participate in a lively and natural discussion among 
them. A total of six in-depth interviews were conducted with respondents from Home of Smiles Centre (a drop-in centre for homeless children), Child Line (a call-in centre for children and youths), Ministry of Public Service Labour and Social Welfare, Harare hospital and a pharmacy. The key informants consisted of male and female experts who provided information on sexual and reproductive issues of youths on the streets. Notwithstanding the triangulated nature of the study, the analysis is more inclined towards a quantitative approach.

A survey was carried out among 202 respondents of both sexes. The sample was arrived at using the following formula: $n=z^{2} p q / e^{2}$. Where $n$ is desired sample size, $\boldsymbol{z}$ is the standard normal deviate set at 1.96 corresponding to $95 \%$ confidence level, $p$ is the response distribution and $q=I-p$ and $e$ is the maximum allowable error (Standard Error) set at 0.05. From a pilot study the average positive response $(p)$ to six questions in the questionnaire that are central to sexual and reproductive health of the youths was $78.4 \%$. Using this value of $p$ a sample size of 259 was obtained. However due to the difficulties associated with locating and reaching the respondents the study only covered 202 respondents, giving a response rate of $78 \%$ (i.e. $(202 / 259) \times 100)$ ).

Snow balling was the sampling design used because there was absence of a complete or reliable sampling frame. A questionnaire was used as a research tool in the survey and it comprised of 7 sections with questions on sexual and reproductive health issues among street youths. The questionnaire was loaded into a real time electronic data collection instrument called "Survey To Go".

The quantitative data were analysed using a statistical package called SPSS. The Chi-square statistic of association was used to test the association between selected sexual and reproduction health issues and background characteristics of the youths. The test was performed at the level of significance $\alpha=0.05$. All qualitative interviews were audio recorded. They were then transcribed before analysis. Themes were developed guided by categories of ideas from literature. Categories were revised continuously with the addition of new responses.

\section{Results}

Socio-Demographic Characteristics of the Respondents

The majority of respondents were male $(61 \%)$. The dominant age group was $15-19$ years (63\%), followed by $20-24$ years (26\%), and $12-14$ years ( $11 \%)$. Thus, $41 \%$ were under the age of 18 years the majority age in Zimbabwe. Ninety -four percent were never married, those separated or divorced constituted $5 \%$. About half $(51 \%)$ had attended but did not complete primary school, $37 \%$ had completed primary school and $10 \%$ had attended but not completed secondary school. Three percent had never been to school. Respondents who were Catholic constituted $31 \%$ of the sample, $29 \%$ were Pentecostals, 18\% were Protestants and 14\% followed the apostolic religion.

\section{Sexual behaviour and current sexual activities}

Ninety-five percent of the respondents reported they had ever had sex ( $94 \%$ males and $97 \%$ females). Nearly half $(48.6 \%)$ of sexually experienced youths had sexual intercourse for the first time by age 15 years, a quarter first engaged in sex between 16 and 17 years of age, $16 \%$ between 18 and 19 years, and about a tenth between 20 and 24 years.

Respondents were asked the age of their sexual partner on their first sexual encounter. The majority of the sexually active youths stated that their sexual partner was between $12-17$ years (76\%). Others reported that their sexual partner was aged between $18-19$ years (14\%) and $20-24$ (10\%). The majority of the respondents $(68 \%)$ indicated that they had more than five lifetime sexual partners (males $71 \%$ and females $65 \%$ ). Five percent had one sexual partner.

About seven out of ten girls reported that their sexual partners were their boyfriend and nearly $60 \%$ of boys reported that they were their girlfriend. The difference in percentages show that street youths have relationships that extend outside of their circle. Thirty-eight percent of males reported that casual acquaintance were their sexual partners, whilst $23 \%$ of females reported the same. Eight percent of females reported that their spouses were their sexual partner while $3 \%$ of males reported the same.

Marital status and education were found to be statistically associated with youth having ever had sex $(p<0.05)$. The lower the educational attainment, the more likely the respondent to have had sex.

Current sexual activity was measured by sexual encounter in the past 12 months preceding the survey. Fifty-nine percent and forty one percent of males and females had had sex within the last twelve months, respectively. Male street children were more sexually active than their female counterparts.

Respondents were asked whether their first sexual encounter was planned. More than half of the respondents (59\%) who had sex had planned their first sexual encounter. Among males and females $54 \%$ and $66 \%$ had done so, respectively. This shows that, to some extent, engaging in sex was not a sponteneous act.

There was an association between background characteristics, educational level $(p=0.002)$ and 
religion $(p=0.004)$ with having had sex in the last 12 months. The respondents who had never been to school (100\%) were more likely to have had sex in the past 12 months compared to respondents who attained primary schooling (84\%) and secondary school (60\%). Respondents from the Apostolic sect were more likely to have had sex in the past 12 months (89\%) as compared to youths who did not belong to any religion (60\%). No significant association was found between last sexual encounter and sex, age and marital status.

\section{Contraceptive use}

Respondents were asked about contraceptive use on their first sexual encounter. Almost a fifth of the youths (19\%) used contraception on their first sexual encounter. Contraceptive use, on first sexual encounter, was lower among males (17.2\%) than among women (22.0\%). The majority of youths who used contraceptives on their first sexual encounter used the male condom (83\%), a sign that the main motive was to prevent both sexually transimitted infections and pregnancy. Other methods used included the pill (4\%) and implant (8\%), an indication that these were more concerned with avoiding pregnancy than prevention of STIs.

Age, marital status and education were found to be statistically associated with contraceptive use on first sexual encounter. The respondents aged 20-24 were more likely to use contraceptives $(26 \%)$ as compared to younger ones aged I2-I4 (I4\%) $(p=0.003)$. The never married respondents were more likely to use contraceptives on their first sexual encounter $(23 \%)$ compared to those married $(0 \%)$ $(p=0.001)$. Respondents who attained higher or tertiary education were more likely to use contraception $(26 \%)$ as compared to those who never went to school (0\%) and those who attained primary education $(20 \%)(p=0.004)$. No significant association was found between use of contraception on first sexual encounter and sex and religion.

About six out of ten respondents (64\%) reported that they had used contraception on their last sexual encounter (62\% among males and $66 \%$ among females). The male condom was used by almost all the respondents (95\%) and implants by about a tenth (II\%). Ninety-eight percent of males and $67 \%$ of females had used the male condom.

Sixty-four percent of the street youths used contraceptives on their last sexual encounter. Age and education were found to be statistically associated with contraceptive use on last sexual encounter $(p=0.00 \mathrm{I})$ with respondents who attained incomplete secondary education more likely to use contraception on their last sexual encounter (78\%) than those who have never been to school (20\%).
Respondents aged 18 and 19 years were more likely to use contraception on their last sexual encounter (7I\%) than the younger ones aged 12 to 14 years $(25 \%)(p=0.004)$. No significant association was found between contraceptive use on last sexual encounter and sex, marital status and religion.

\section{Pregnancy and abortion}

Respondents were asked questions pertaining to knowledge of pregnancy, attitudes towards abortion and lifetime number of pregnancies. Seven out ten (73\%) of female respondents agreed with the statement that "From one menstrual period to the next, there are certain days when a woman is more likely to become pregnant". However of concern were $32 \%$ who agreed with the statement that "One cannot fall pregnant during first sexual intercourse".

The youth were asked about their opinion on abortion. Mixed views about abortion were put forward. About a third (32\%) of street youths believed that it depended with the situation for one to abort, $29 \%$ believed that abortion is murder. Approximately a fifth of the street youths said abortion was a crime (24\%) and $16 \%$ believed that some situations force female youths to abort. Information gathered from Focus Group Discussions showed that poor living conditions and their economic situation forced them to abort and also they aborted because they were not ready to be mothers. Another motivation for abortion was that pregnancy prevented them from having sex for money. They also pointed out that they engage unqualified people to perform the abortions.

Female respondents were asked if they had ever been pregnant. Forty-four percent reported that they fell pregnant once in their lifetime, $38 \%$ had had two pregnancies and $18 \%$ had had more than two pregnancies.

\section{Sexually transmitted infections (STIs) and HIV and AIDS}

Overall $88 \%$ of respondents were aware of STls ( $91 \%$ among females and $86 \%$ among males). Fiftyfour percent of the respondents who were aware of STls heard the information from health workers, $18 \%$ from family and friends, $17 \%$ from teachers and $9 \%$ from religious circles. The least mentioned source of information on STls were TV, billboards, radio and brochures (2\%). About half (48\%) percent of all the youths had suffered from an STI, with $51 \%$ and $43 \%$ of males and females having suffered from it, respectively. Qualitative interviews reported that street children commonly suffer from STIs and they either visit the clinic or traditional healers for treatment. The most common type of STI was Syphilis, with $64 \%$ of those who had suffered an STI 
having suffered from it. A third suffered from Gonorrhoea, $5 \%$ and $2 \%$ suffered from Herpes and were infected with HIV, respectively. Almost all street children correctly identified symptoms of STIs.

Knowledge of how HIV is transmitted was accurate with $(98 \%)$ of respondents mentioning unprotected sex (males - 98\%) and (females 100\%). Seventy-four percent mentioned contaminated blood and II\% mentioned mother to child transmission.

The majority of respondents mentioned that HIV and AIDS could be treated by going to the hospital/health institution to get medicines (99\%), followed by taking traditional herbs (38\%).

Three-quarters of respondents agreed that a person with TB can also have HIV and this percentage was higher among females than males. Almost half (49\%) of respondents obtained information on HIV and AIDS from health care workers. This was followed by family and friends (23\%) and school teachers (I $2 \%)$.

\section{Alcohol and drug use}

Nine in ten respondents took alcohol. The mpercentage was $89 \%$ among males and $92 \%$ among females.

Youths were asked if they took drugs. Eighty-nine percent responded in the positive. Ninety-four percent of males and $81 \%$ of females took drugs, respectively

The study investigated whether there was an association between alcohol and drug use and sexual activity in the last 12 months. Alcohol and drug use were found to be statistically associated with current sexual activity. Street youths who consumed alcohol were more likely to have had sex in the past 12 months (85\%) compared to those who did not consume alcohol $(16 \%)(p=0.034)$. Respondents who used drugs were more likely to have had sex in the past 12 months $(77 \%)$ than those who did not use drugs $(23 \%)(p=0.003)$.

The study also investigated the association between alcohol and drug use and contraceptive use. Alcohol and drug use were found to be statistically associated with current contraceptive use. Respondents who consumed alcohol were less likely to use contraceptives compared to those who did not consume alcohol $(p=0.002)$. Street youths who used drugs were less likely to use contraceptives as compared to those who did not use drugs $(p=0.004)$. Further analysis showed that alcohol consumption was found to be statistically associated with pregnancy. Female respondents who consumed alcohol were more likely to fall pregnant as compared to those who did not consume alcohol $(p=0.003)$.

\section{Access to SRH}

Twenty-eight percent of respondents reported that they had access to Sexual Reproductive Health. More youths among males (64\%) than females (36\%) had access to $\mathrm{SRH}$ services.

Thirty-nine percent reported they had visited reproductive health facilities, $35 \%$ said that it was easy to get information or services on contraceptives and $17 \%$ agreed that reproductive health facilities were user friendly.

Nevertheless, a number of street youths reported that access to SRH services was difficult. They mentioned that reproductive health workers were neither friendly nor confidential. Of the interviewed street youths, none had received Antenatal care.

Costs were also cited as a reason why SRH services were not easily accessible. In an FGD it was revealed that sometimes the youths had to pay a fee before they were attended to. As a result, it was hard to go to hospitals because of the cost of service and transport. The majority of the respondents, above $90 \%$, reported that they obtained SRH services from either Government clinics or clinics run by NonGovernmental Organisations, respectively. Thirty percent of the street youths mentioned that they could access SRH services at private clinics. Regardless of the affordability of Government hospitals, street youths preferred to use clinics run by NGOs and a well-wisher, because they were more comfortable with the later.

Access to SRH services was found to be statistically associated with pregnancy. The majority of females who had access to SRH services never fell pregnant (74\%) and $14 \%$ of those who had access to SRH services had fallen pregnant $(p=0.002)$. Access to SRH services was found to be statistically associated with contraceptive use. The majority of respondents who had access to SRH services were more likely to use contraceptives ( $92 \%$ ) as compared to those who had no access to SRH services $(p=0.002)$.

\section{Discussion}

Almost all youths interviewed engaged in sex. Most of the sexual activity was for survival. Youths on the streets were engaging in sexual activity at an early age, as $49 \%$ had had sex by the age of 15 years. The study also found that the mean age at first sex was I5 years. These findings are similar to a study in Malawi which noted that sexual behaviours begin during adolescents (ICF International \& NSO, 20I7) and another one by UNICEF (2016), which showed that in Lesotho, age at first sexual debut was as young as 14 years. The age at first sexual activity of youths on the streets is much lower than of the general population as reported by ZIMSTAT and ICF (2016). 
The age of consent for sexual activity in Zimbabwe is 16 years. This shows that most of the youths on the streets of Harare are engaging in sexual activity before the legal age of consent. Besides enaging in sex with boyfriends and girlfriends, qualitative discussions showed that some under-age street boys had sex for money with well-to do older women.

The study showed an inverse relationship between educational attainment and coital frequency among the youths. This finding confirms results found by (Zuilkowski \& Jukes, 20II) when they reviewed studies carried out in sub-Saharan Africa, on the subject. The reason why youths who have attained higher education were less likely to indulge in sexual activities could be that in school youths are taught about the dangers of sexual activity in comprehensive sexuality education.

Reasons for multiple sexual partners varied from an expression of manhood for boys, and largely poor living standards and poverty for girls. Girls engaged in sexual activities with boyfriends to be taken care of and to be protected on the streets. Peer pressure also contributed to the phenomenon of multiple partners, as noted by Widman et. al., (2016) in another study.

The rate of contraceptive use on last sexual encounter among youths on the streets of Harare were higher as compared to global levels and for Zimbabwe, as reported by ZIMSTAT and ICF (2016). There is a concern, however, for the low use of contraceptives on first sexual encounter, which puts street youths at high risk of STIs, including HIV, and pregnancy.

Results also showed that education is an important determinant of contraceptive use. Education equips youths with information and knowledge about contraceptives, safe sex and other important behaviours, which protect them from STI infection, because of its pervasiveness. This finding is similar to the study by Mandiwa, et al., (2018) who also found a strong link between educational attainment and contraceptive use.

Contraceptive use among the never married was relatively high, almost the same as the national level. This may be an awareness that having sex with someone who is not your spouse or regular partner exposes one to the risk of infection. Contraceptive use was low among married youths because they believed that not using contraceptives was a show of trust and love. Married youths assumed that there was no need for them to use contraceptives. This is a matter of concern because of the exposure to the risk of contracting HIV.

The male condom was mostly used by youths both in the first sexual encounter and subsequent ones. The reasons for non-use of condoms were also mentioned in the qualitative findings, where youths stated that they believed sex without condoms was more exciting than with condoms. However the cost of accessing condoms, as a hindrance to their use, was also mentioned by the youths.

The result that age is protective of getting pregnancy could arise from knowledge and experience on how to avoid pregnancy that comes with age. The importance of education as a factor that reduces the likelihood of getting pregnancy is amplified by the finding that female youths who had never been to school were more likely to become pregnant, compared to those who had attained higher educational levels. This could also be reflective of the lack of reproductive education for girls on the streets, as attending school could have exposed them to reproductive health education.

The fact that girls abort because of the appalling living standards and that they fear of becoming mothers at an early age, speaks to the unmet need for contraceptives for these girls. Reliance on unsafe abortion techniques puts these youths at risk of health complications and psychological stress in the absence of adequate counselling services.

While Munjanja (2012) found that over two thirds of female youths, in general, received at least one antenatal care (ANC) visit, non-attendance of ANC by street youths poses the risk of attendant health problems. Antenatal care is important because it protects the mother and unborn child from conditions that may threaten their lives. It helps to identify and manage complications such as preeclampsia, tetanus toxoid immunization and intermittent preventive treatment for malaria during pregnancy. Antenatal care also identifies and manages infections such as HIV and its transmission to the unborn child, Syphilis and other STIs.

The high awareness of HIV and AIDS among street youths did not however translate into positive action, as the majority of them still engaged in risky sexual behaviour, such as non-use of protection and contraceptives with multiple sexual partners. Peer misinformation about sex and the use of contraception puts the youths at high risk of pregnancy, STIs and HIV. This shows that street youths still need to be educated on contraceptive use and also on the effects of risky sexual behaviour.

While studies identify the school as one of the important sources of information on HIV and AIDS (Sehnem, et al., 2018), the main source of this information for street youths are health workers. Unfortunately, the youths reported that they were not free to discuss their health issues with health workers, especially in public hospitals due to fear of lack of confidentiality. 
The most common type of STI suffered by street youths was Syphilis, which confirms findings by the WHO (2016) but contrary to the study conducted by Barbin et.al (2015) in South East Nigerian where Chlymadia and Trichomasis were reported to be common among female youths. The health-seeking behaviour of youths infected with STls exposes their lack of knowledge about treatment, as most of them approached traditional healers for remedy.

The association between drug and alcohol abuse, and risky sexual behaviour was highlighted by the study, especially engagement in unprotected sex and non-use of contraceptives. This was also confirmed by Ruparanganda (2008). Unfortunately for young girls, intoxication was used as a weapon by boys to abandon the use of contraception and protection during sexual encounters. This puts the girls at high risk of contracting STIs including HIV and unwanted pregnancies.

Low levels of access to SRH services were reported, especially services accessed through public health institutions, regardless that they were affordable. They actually preferred to receive services from a well-wisher than from government clinics because of the unfriendly environment that prevailed at public institutions and also because of lack of confidentiality. This finding confirms that by Mangwentsu, et al., (20I5) who reported that youths in Zimbabwe were neither well received nor comfortable with accessing SRH services, mainly in government owned clinics.

\section{Conclusion}

Youths in the streets were engaging in sexual activity early, with boyfriends or girlfriends of the same age. Some male youths also indulged in sexual activities with older women. The study identified peer pressure and poor living standards as the main push factors towards sexual activity among youths. Contraceptive use was low at first sexual encounter, showing that youths on the streets of Harare were having sexual intercourse early without protection. Age, sex and marital status were associated with contraceptive use. The youths had multiple sexual partners and were also not using contraceptives, putting themselves at high risk of contracting STIs, including HIV, and of falling pregnant. This has a negative impact on their health as well as their future lives in relation to education and employment. Educational attainment was related to the risk of falling pregnant. Alcohol and drug abuse was of concern among street youths because it led to unplanned and unprotected sex. Young females who stayed on the streets were not utilising Antenatal care services. Access to SHR services was limited in terms of contraceptives. Attitudes of health workers was serving as a barrier to accessing these services.

A lot needs to be done to improve sexual and reproductive issues among street youths in Harare, in particular, and in Zimbabwe, in general. The Government of Zimbabwe and the Ministry of Health and Child Care should recognise the sexual and reproductive health needs of youths who live on the streets. More importantly health education and education on contracetives should be extended to youths on the streets. Contraceptives, especially condoms, should also be made easily available to the youth for both pregnancy prevention and protection from STIs. The Ministry of Health and Child Care should also ensure that street youths have access to health services in public institutions without any hindrances.

\section{References}

Bachanas, P. J., Morris, M.K., Lewis-Gess, J.K., SarettCuasay, E.J., Sirl, K., Ries, J.K. \& Sawyer, M.K., 2002. Predictors of Risky Sexual Behaviour in African American Adolescents Girls: Implications for Prevention Interventions. Journal of Pediatric Psychology, 27(6), pp. 5I9-530.

Bhatasara, S., Changadeya, T. \& Chevo, T., 2013. An Exploratory Study of Male Adolescent Sexuality in Zimbabwe: The Case of Adolescents in Kuwadzana Extension, Harare. Journal of Anthropology, Volume 2013.

Centers for Disease Control and Prevention, 2017. Sexually Transmitted Disease Surveillance 2016, Atlanta, Georgia: National Center for HIV/AIDS, Viral Hepatitis, STD, and TB Prevention Division of STD Prevention.

Centre for American Studies, 2010. www.americanprogress.org/wpcontent/uploads/issues/2010/06/pdf/gbt/youthho melessness.pdf.. [Online].

Chikoko, V., Chikoko, E., Muzvidziwa, V. N. \& Ruparanganda, W., 2016. Non-government organizations response to substance abuse and sexual behaviors of adolescence street children of Harare Central Business District.. African Journal of Social Work, 6(2), pp. 58-64.

Clement, D., 1992. A Social Safety Net for the Chronically Poor? Zimbabwe's Public Assistance in the 1990s,. NY, USA: Fordham University Bronx,.

Conklin, K., 2012. Adolescent Sexual Health and Behaviour in the United States: Positive Trends and Areas in need of Improvement., Washington D.C.: Advocate for Youth.

Creanga, J. \& Hartman, K., 2015. Reproductive rights and Wrongs. New York: Haper and Row..

Gemechu, B. G. et al., 2009. The correlation between alcohol consumption and risky sexual 
behaviours among people living with HIV/AIDS. NCBI, I4(2), pp. 90-I00.

George, A., 2009. Beyond Sugar Daddies: Intergenerational Sex and AIDS in Urban Zimbabwe.. AIDS Behaviour, Volume 15, pp. I275-। 284.

Guttmacher, S. \& Marfatia, Y., 2016. Adolescent HIV/AIDs :Issues and challenges.. Indian Journal of Sexual Transmitted Diseases, Volume 3, pp. I-I0.

ICF International \& NSO, 2017. Malawi demographic and health survey 2015-16., Zomba, Malawi, and Rockville, Maryland, USA:: NSO and ICF International.

lyer, P., Clarke, D. \& Aggleton, P., 2014. Barriers to HIV and sexuality education. Health Education, I I4(2), pp. I I8-I 32.

James, J., Schlomer, G., Ellis, B. J. \& Garber, J., 2012. Sex-Specific Pathways to Early Puberty, Sexual Debut, and Sexual Risk Taking: Tests of an Integrated Evolutionary-Developmental Model. Development Psychology, 48(3), pp. 687-702.

Kumi-Kiyereme, A., Awusabo-Asare, K. \& Dareth, E. K., 2014. Attitudes of gatekeepers towards adolescent sexual and reproductive health in Ghana. African Journal of Reproductive Health, I8(3), pp. 142-53.

Mandiwa, C., Namondwe, B., Makwinja, A. \& Zanawe, C., 2018. Factors associated with contraceptive use among young women in Malawi: analysis of the 2015-16 Malawi demographic and health survey data. Contraception and Reproductive Medicine, 3(I2).

Mangwentsu, E. A., Kwaak, A. V., Zwanikken, P. \& Zoaka, A. I., 2015. Exploring the factor influencing adolescents sexual behavior in Ploateau state Nigeria., Amsterdam, the Netherlands: Royal tropical Institute, Kit Health,.

Margaret, T. \& Chafetz, J., 20I5. The gender division of labor of the reproductive of female disadvantage: toward an integrated theory.. Journal of Family Issues, Volume 9, pp. |08-I3I.

Mburu G., Hodgson I.,Kalibala S., Haamujompa C., Cataldo F., Lowenthal E.D.,\& Ross D., 2014. Adolescent HIV disclosure in Zambia: barriers, facilitators and outcomes. Journal of the International AIDS Society, I7(I), pp. I-9.

Ministry of Health and Child Care, 2016. Adolescent Sexual and Reproductive Health (ASRH) Strategy (2010-20/5), Harare, Zimbabwe: s.n.

Moyo, G. \& Zvoushe, H., 20I4. Ecological self-image and behaviors of children living on the streets of Harare.. Development Southern Africa. Towards Resilient urban Communities, 33(I), pp. 35-36.

Muller, A. \& Moult, K., 20I4. Sexual and reproductive health care for teens: Guidelines for health, Cape Town, South Africa: UCT.
Munthali, A. C., Chimbiri, A. \& Zulu, E., 2004. Adolescent Sexual and ReproductiveHealth in Malawi: A Synthesis ofResearch Evidence, New York \& Washington: The Alan Guttmacher Institute.

Mutemasango, T. J., 2014. Struggling to survive: $A$ study of street children in Zimbabwe, Harare: UNICEF.

Ngwenya, S., 2016. Communication of reproductive health information to the rural girl child in Filabusi, Zimbabwe. African Health Sciences, 16(2), pp. 45I-46I.

Okonofua, F. E., 2016. Reproductive health challenges in Africa. Confronting the challenge of reproductive health in Africa. Boca Raton. Florida. USA: Brown Walker Press.

Ruparanganda, W., 2008. The tragedy of procrastinating? A case study of sexual behaviour patterns o street youth of Harare, Zimbabwe: In the era of HIV and AIDS Pandemic, Harare: University of Zimbabwe.

Sanchez-Paez, D. A. \& Ortega, J. A., 2018. Adolescent contraceptive use and its effects on fertility. Demographic Research, 38(Article 45), pp. 1359-1 388.

Sehnem, G. D., Pedro, E. N., Ressel, L. B. \& Vasquez, M. E., 2018. Sexuality of adolescents living with HIV/AIDS: sources of information defining learning. Escola Anna Nery Journal of Nursing, 22(I), p. Online.

Shewmaker, J. W., 2015. Sexual efficacy: What is it?. [ HYPERLINK "https://jennifershewmaker.com/" https://jennifershewmaker.com/

[Accessed 10 February 2019].

Svodziwa, H., 2016. Adolescent Street Children's Self Image, Harare: University of Zimbabwe, Department of Psychology.

UNDESA, 2013. Adolescent Fertility since the International Conference on Population and Development. CAIRO, ICPD.

UNFPA, 2016. Universal Access to Reproductive Health. Progress and Challenges, New York.UNICEF, 2016. Annual report. Adolescent's sexual and reproductive health report: What the data say., New York.

United Nations Children's Fund \& Zimbabwe National Statistics Agency, 2014. Zimbabwe Multiple Indicator Cluster Survey 2014, Harare: United Nations Children's Fund; Zimbabwe National Statistics Agency.

United Nations Population Fund, 2013. Motherhood in Childhood. Facing the challenge of adolescent pregnancy, New York. USA.

United Nations, 2016. (The street child project) http//www.thestreetchildproject.org/statistics/.

[Online] [Accessed I 2 February 2019]. 
Volpi, B., 20I4. Children of the Streets. Why are they in the streets? How do they live?. Economics and sociology, 8(4), pp. I34-I38.

Watson, J., 20ll. Understanding survival sex: young women, homelessness and intimate relationships. Journal of Youth Studies, I4(6), pp. 639-655.

Wekwete, N. N., 2010. Adolescent Pregnancy Challenges in the era of HIV and AIDS: A Case Study of a Selected Area in Zimbabwe. Addis Ababa: OSSREA.

Widman, L., Choukas-Bradley, S., Helms, S. W. \& Prinstein, $\quad M . \quad 2016$. www.ncbi.nlm.nih.gov/pmc/articles/PMC4766019/ .[Online] [Accessed 9 February 2019].

Woog, V. \& Kagesten, A., 2017. The sexual and reproductive health needs of very young adolescents aged 10-14 in developing countries: What does the evidence show?, New York: Guttmacher Institute.

World Health Organisation, 2015. Sexual and reproductive health. Arshie: Thegatehouse central.Arshie central hospital.

World Health organization, 2016. Sexual and reproductive health. New York.USA: WHO.

ZIMSTAT \& ICF, 2016. Zimbabwe Demographic and Health Survey.(2015), Calverton, MD, USA: ZIMSTAT and ICF International.

Zuilkowski, S. \& Jukes, M. C., 20II. The impact of education on sexual behavior in sub-Saharan Africa: A review of the evidence, Florida: Department of Educational Leadership and Policy Studies: Florida State University Libraries. 